\title{
Development of Sichuan Brocade with Imitating Embroidery Effect Based on Free-Floats Interlacing Weave
}

\author{
Dekun Ma1, Ming Cheng1, Dan Zheng1, Xiaomin Fan1, Weijie Wang1,2,3*, Jia Fang1,2 \\ ${ }^{1}$ Sichuan Academy of Silk Sciences, Chengdu, China \\ ${ }^{2}$ Sichuan Provincial Silk Engineering Research Center, Chengdu, China \\ ${ }^{3}$ Faculty of Textile and Garment Engineering, Sichuan University, Chengdu, China \\ Email: ^980854683@qq.com
}

How to cite this paper: Ma, D.K., Cheng, M., Zheng, D., Fan, X.M., Wang, W.J. and Fang, J. (2020) Development of Sichuan Brocade with Imitating Embroidery Effect Based on Free-Floats Interlacing Weave. Journal of Textile Science and Technology, 6, 11-18.

https://doi.org/10.4236/jtst.2020.61002

Received: November 23, 2019

Accepted: December 14, 2019

Published: December 17, 2019

Copyright $\odot 2020$ by author(s) and Scientific Research Publishing Inc. This work is licensed under the Creative Commons Attribution International License (CC BY 4.0).

http://creativecommons.org/licenses/by/4.0/

\begin{abstract}
Owing to the diversity of consumer's demand, the traditional Sichuan brocade products have to be innovated in order to survive in a competitive environment. Since the construction of traditional Sichuan brocade was composed of basic-weave, the surface of the fabric shows a regular interweaving planar texture and is difficult to represent a three-dimensional effect. Inspired by embroidery handcraft, this paper attempts to achieve the embroidery-like effect on the fabric through the jacquard process. Based on the multi-backed structure of traditional Sichuan brocade, we adopted the zoned-combination design mode and added extra free-floats interlacing weave in the area where we want to show the embroidered effect and arranged the interlacing points by referring to the feature of the pattern. As a result, designed Sichuan brocades by this method are capable of displaying embroidered effect with high realism and three-dimensionality. This approach improves the artistic effect of the traditional Sichuan brocade and provides a technical reference for further texture design of jacquard fabrics.
\end{abstract}

\section{Keywords}

Free-Floats, Interlacing Weave, Imitating Embroidery, Sichuan Brocade

\section{Introduction}

Different from other famous silk brocades (i.e. Song brocade and Yun brocade) in China, Sichuan brocade has the longest history and is the first milestone of Chinese brocade [1]. As a jacquard fabric, the Sichuan brocade usually adopts multi-backed wefts construction and combines the process of adding extra weft 
and replacing the weft to generate a multi-colored pattern effect on the surface of fabric [2]. However, this traditional fabric cannot meet the needs of modern consumers, so it is extremely urgent to innovate traditional Sichuan brocade.

The prior studies proposed that innovation in pattern and texture design was essential for the innovation of traditional brocade [3]. Predecessors have done a lot of research work on the pattern and color innovation of jacquard fabric. Some research focused on the full-color digital jacquard fabric design [4] [5] [6] [7], others developed the pattern innovation method based on full-color structure and polymeric optical fiber [8] [9]. Different from pattern and color innovation, there were few achievements in texture innovation, especially in the development of imitating embroidery brocade. Wang et al. introduced a method to design jacquard fabrics with quilting seam effect [10]. However, the fabric effect formed by their approach unable to express large-scale embroidery effect. Li et al. realized the high convexity effect on the fabric surface by using a special double layer weave. However, the biggest problem with this fabric is that it does not show the feature of embroidery stitches [11].

In conclusion, there are few reports about innovation of brocade with an embroidery-like effect, especially in Sichuan brocade. In this study, the Sichuan Brocade with imitating embroidery Effect was obtained based on the utilization of multi-backed construction and free-floats interlacing weave. The application of the jacquard computer-aided design (CAD) system in pattern design and zoned-combination design mode made it possible to create the weaving and embroidering effect on the same fabric.

\section{Design Principles and Methods}

The appearance of fabric changes along with the fabric construction of weaves. There are four main types of traditional jacquard fabric structure: single-layer, backed structure, double-layer and multi-layer. For imitating embroidery effect, the weft threads with long floats will be appropriate to adopt. At the same time, in order to maintain the stability of the fabric, the weft-backed weaves were used after the consideration. The design principles and methods of embroidery-like effect Sichuan brocade will be investigated in the following sections.

\subsection{Covering Principle of Weft-Backed Weave}

In compound fabric construction, different fabric weave designs will have an effect on the covering relationship between the weft threads, so that the surface of the fabric will form three different effects: 1) all-backed; 2) partial backed; 3) no backed. As shown in Figure 1. In order to generate the embroidered texture on the surface of the fabric, it is necessary to use the all-backed weave to cover the backing layer of the fabric in the embroidered area completely. Because the face weft-floats of the imitation embroidery area is far longer than the backing weft-floats, in terms of theory, the surface of the fabric will only deliver the face weft's color information. 


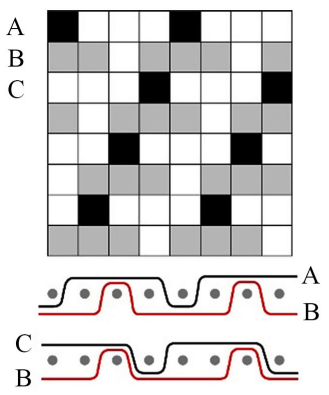

(a) all-backed

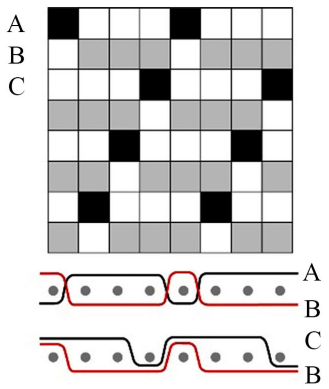

(b) partial backed

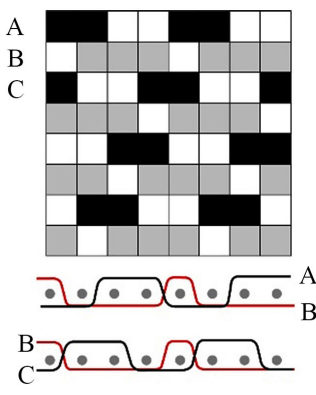

(c) no backed

Figure 1. Weave design for woven fabric with two wefts.

Figure 2 shows a schematic diagram of the color development of the weft seven backed weaves. From left to right, it shows the weave diagram, the interwoven structure diagram, the surface visual effect, and the weft cover relationship, respectively. The figure shows that the longest one of the seven wefts will cover the other six wefts, so only the color information of the weft with the longest float can be seen on the fabric surface.

\subsection{The Weave Design Principle of Imitating Embroidery Texture}

The weave design of the imitating embroidery texture is based on the covering principle of the above-mentioned weft-backed weave compound construction. This paper takes the giant panda Sichuan brocade as an example to introduce the weave design principle of imitating embroidery texture. The artistic characteristics of embroidery products are mainly reflected by the combination of different-length stitches and the change of stitching direction in different embroidery themes. Therefore, it is necessary to consider the combination and the direction arrangement of the stitches when dealing with different pattern themes in the weaving design process. Arranging interlacing structure with free-floats weft threads in the weaving design process will be an effective method to imitate embroidery stitches effect. The interlacing weave can be designed according to the embroidery stitch method, such as Two-Two stitch, Two-Three stitch and ThreeThree stitch, etc. The stitch effects are shown in Figure 3.

Taking the effect of Two-Three stitch as an example. We can arrange the interlacing points at the joint between the stitches when designing the interlacing structure, as shown in Figure 4.

Since it is impossible to establish a free-floats interlacing weave through the weave repeat unit in the jacquard fabric CAD software, it is necessary to design free-floats interlacing points according to characteristics of the pattern manually. We can finally obtain the imitating embroidery effect of the fabric by filling the free-floats interlacing weave in the imitating embroidery area of the pattern and weaving by jacquard loom.

In the design process of the giant panda Sichuan brocade paint, in addition to designing the interlacing weave points according to the length of the stitches, it is also necessary to consider the natural growth tendency of the panda hair to 
guide the design of the interlacing points. Because the direction of the weft thread restricts the direction of the stitches, so it will be difficult to change the direction of stiches just like the embroidery process. In order to represent the effect of natural hair growth direction on the final fabric surface, this paper investigated the natural growth tendency of the giant panda's hair, and designed the contour of the animal hair according to the natural growth tendency of the animal hair. As shown in Figure 5. Through the natural torsion of the outline of the imitating embroidery area, a visual effect of the natural growth of the hair is produced after the free-floats interlacing weave is laid.

In addition to considering the natural growth tendency of the outer contour of the hair area, it is also necessary to embody the growth trend of the hair in the hair area by interlacing points design. As shown in Figure 6(a), the hair of the giant panda can be divided into 18 groups according to the growing trend, and the joint between each group is the position to set the interlacing points, as shown in Figure 6(b). The final product presents a natural hair growth effect by grouping the hair regions according to their natural growth direction and designing the interlacing points according to the outer contour curve of each group.

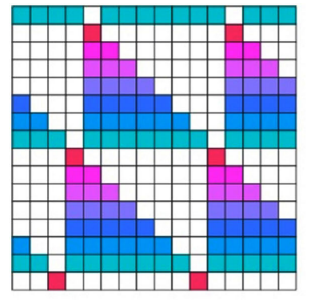

Weave diagram

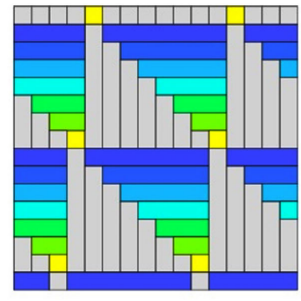

Interwoven structure diagram

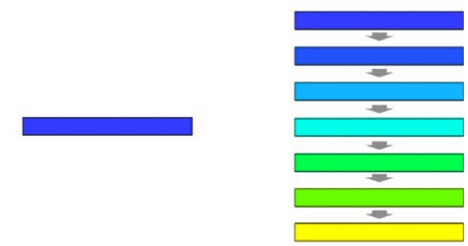

Surface visual effect

Weft cover relationship

Figure 2. Covering principle of weft seven backed weave.

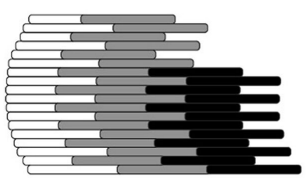

Two-Two stitch

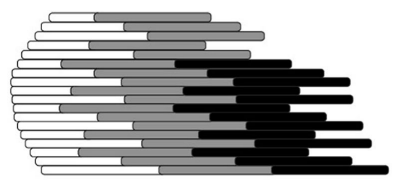

Two-Three stitch

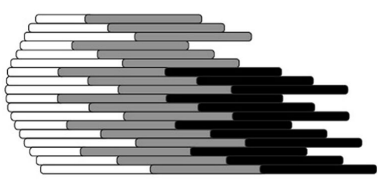

Three-Three stitch

Figure 3. Embroidery stitch method.

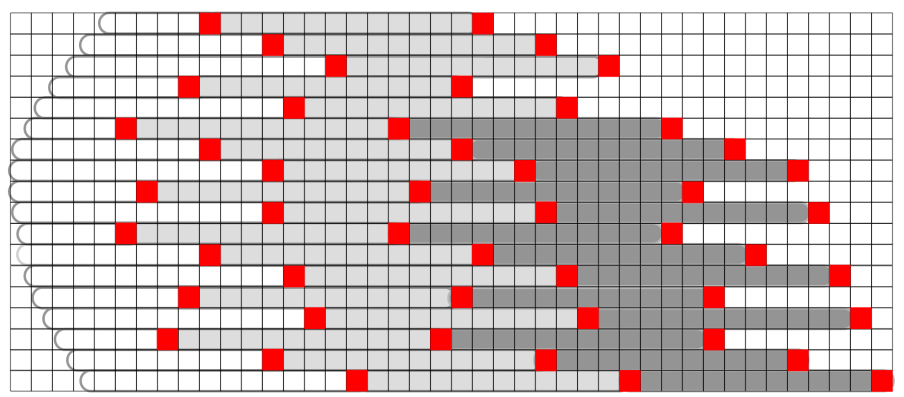

Figure 4. Interlacing weave point design. 


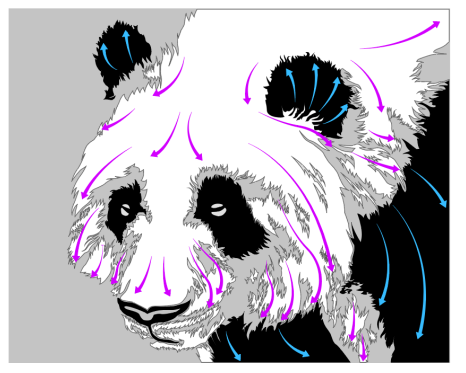

Figure 5. The natural growth trend of animal hair.

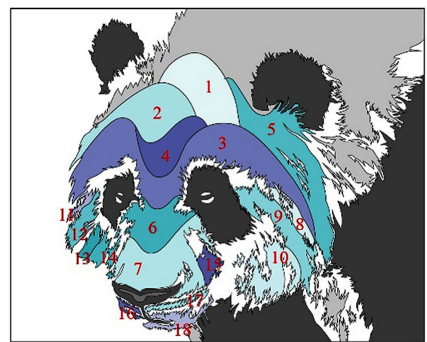

(a)

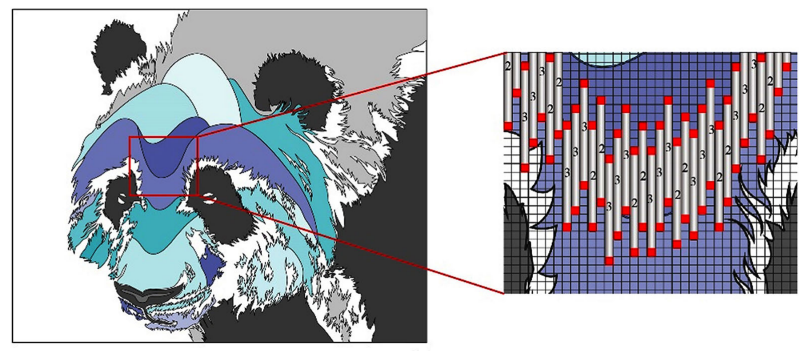

(b)

Figure 6. (a) The giant panda head hair group; (b) Interlacing point design at group joint.

\section{Design Process}

This paper takes the giant panda theme Sichuan brocade as an example to explain the design process. In this paper, patterns were divided into two areas: conventional area and imitating embroidery area. As shown in Figure 7. Based on the multi-backed construction, the weft threads are interwoven with warp threads by normal composite weave in conventional area, whereas the weft threads are interwoven with warp threads by free-floats interlacing weave in imitating embroidery area. To this end, patterns and weaves should be designed using a jacquard fabric CAD system. Conventional area and imitating embroidery area must be edited and modified independently in the jacquard CAD system, and then merging the two zones to produce the final process file.

The design process is divided into three steps. As shown in Figure 8. At first, the conventional area is processed according to a normal technology to form a corresponding pattern card 1 . Secondly, the imitating embroidery area (hair area) is processed and the corresponding jacquard card 2 is obtained. Finally, the pattern card 1 is superposed onto pattern card 2 and the final pattern card 3 is obtained. 


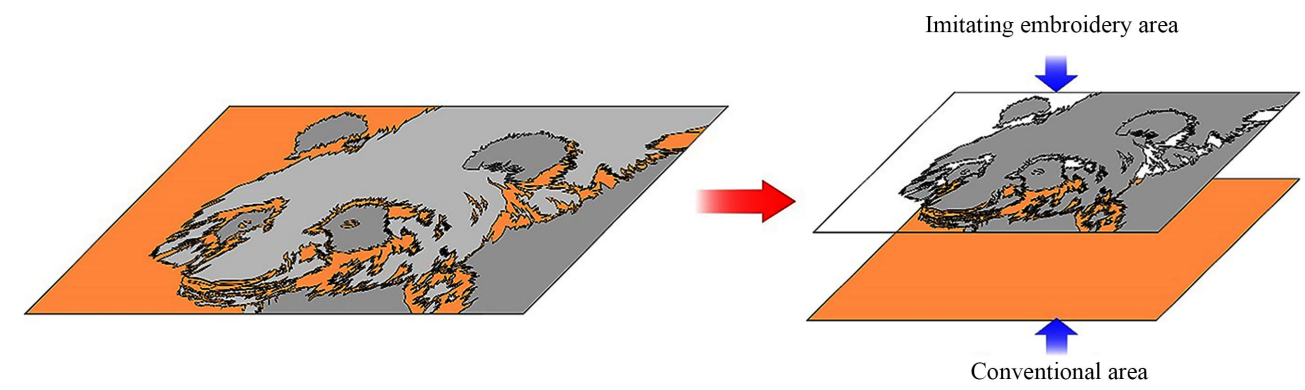

Figure 7. Design zones of giant panda Sichuan brocade paint.

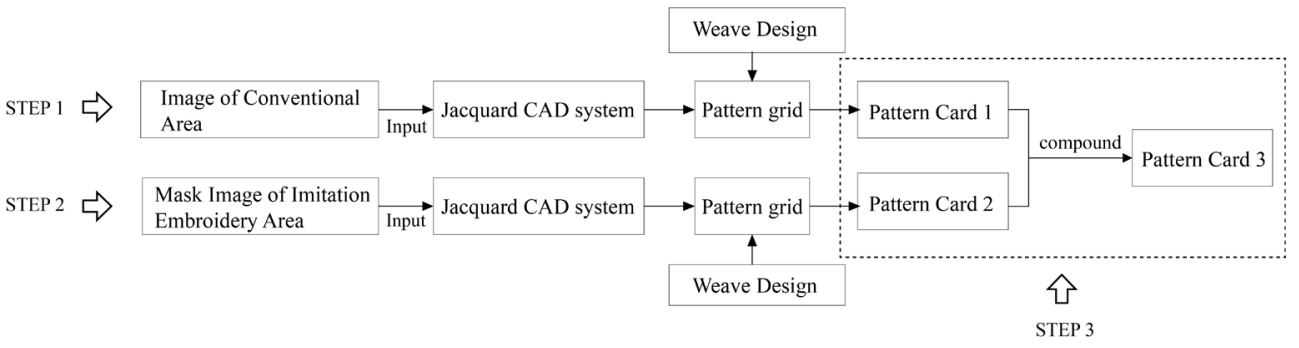

Figure 8. Work flow of imitating embroidery effect Sichuan brocade design.

In the first step, the design pattern or the scanned pattern is edited in Photoshop and the image is saved as a bitmap file. Then, in the jacquard fabric CAD, the graphic processed by the Photoshop software (conventional area) is subjected to color separation processing and the color numbers are combined into $\mathrm{n}$ colors, the corresponding pattern grid file is created. Then, according to the machine installation information setting sample card, combined with the pattern grid file and sample card information to generate a pattern card file, the pattern card file is named pattern card 1. For example, if the giant panda jacquard fabric is the weft seven backed weaves, the number of colors in the conventional area are designed in five colors, that is, $\mathrm{n}=5$. When the pattern card file is generated, the weft lines of the five colors are respectively set on the first, third, fourth, fifth, and sixth weft spaces, and the two and seven weft spaces are reserved for the pattern card 2.

In the second step, the animal hair area is extracted by using the mask tool in Photoshop software to generate a bitmap with only m kinds of colors. For example, a panda has only two colors, so $\mathrm{m}=2$. According to the size of the animal figure in the hair area, an interlacing weave with free-floats is set and a corresponding pattern grid file is created. Then, the $\mathrm{m}$ colors are distributed to the empty weft-backed of the pattern card file 1 , and the pattern file 2 is generated according to the machine sample card information.

Finally, according to the initial machine sample card, an alternate machine sample card is created in which has the pattern needle except for function needle. According to the alternate machine sample card, the pattern card 1 and the pattern card 2 are combined to generate a complete final pattern card 3 containing $\mathrm{n}+\mathrm{m}$ colors. 


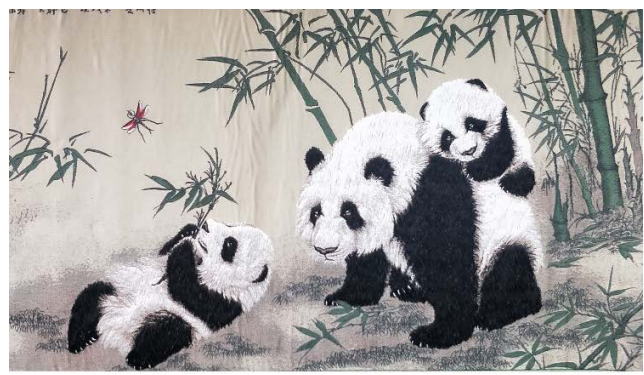

(a)

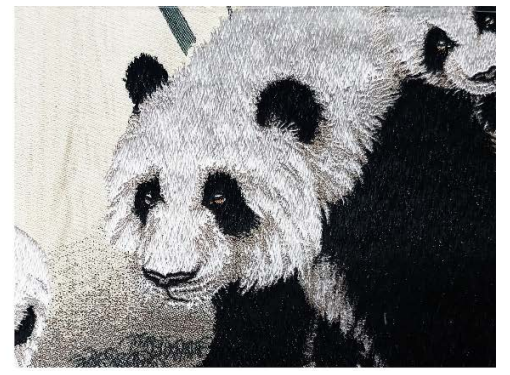

(b)

Figure 9. The giant panda Sichuan brocade and detailed effects.

\section{Implementation}

By arranging the weave design of the conventional area and the imitating embroidery area, it is possible to weave the jacquard fabric with the weaving and embroidering effect on the same fabric surface.

Figure 9 shows an example of an imitating embroidery Sichuan brocade and a detail of a fabric surface woven by the method of this paper. The effectiveness and feasibility of the proposed method can be proved by weaving examples. It can be observed from Figure 9(b) that the panda's hair area is designed with free-floats interlacing weave, thus forming a relatively stereoscopic and realistic hair effect.

\section{Conclusion}

Imitating embroidery effect Sichuan brocade is a new breed of jacquard fabric based on weaving technology and embroidery technology. Such fabric both has weaving and embroidering effect, and can be produced on a jacquard loom by using a multi-backed fabric structure. The design method of Sichuan brocade with an imitating embroidery effect was developed by using the mode of zonecombination design. These make it possible to create different effect on the same fabric. The result of this study could be able to improve the artistic value of the Sichuan brocade products and provide new design ideas for the development of the characteristic brocade products in the future.

\section{Funding}

This work was supported by Sichuan science and technology program (No. 2018YSZH0013 and No. 2018GZ0376).

\section{Conflicts of Interest}

The authors declare no conflicts of interest regarding the publication of this paper.

\section{References}

[1] Qian, X.P. (2011) Analysis on Characteristics of Shu Brocade, Song Brocade and Yun Brocade. Journal of Silk, 48, 1-6. 
[2] Zhu, L.R. and Zhang, X.G. (2010) Probe on the Design of Its Configuration and Texture and Color of Emulation Sichuan Brocade Paint. Shanghai Textile Science \& Technology, 38, 48-49.

[3] Wang, L.F. and Yu, X.Q. (2016) Brocade Evolution, Inheritance and Innovation Design. Journal of Silk, 53, 52-59.

[4] Ng, F. and Zhou, J. (2009) Innovative Layered-Combination Mode for Digital Jacquard Fabric Design. Textile Research Journal, 79, 737-743. https://doi.org/10.1177/0040517508090482

[5] Ng, F. and Zhou, J. (2008) Full-Color Compound Structure for Digital Jacquard Fabric Design. The Journal of the Textile Institute, 101, 52-57. https://doi.org/10.1080/00405000802231291

[6] Ng, F. and Zhou, J. (2009) A study on Figured Double-Face Jacquard Fabric with Full-Color Effect. Textile Research Journal, 79, 930-936. https://doi.org/10.1177/0040517508095603

[7] Ng, F., Kim, K.R., Hu, J.L. and Zhou, J. (2014) Patterning Technique for Expanding Color Variety of Jacquard Fabrics in Alignment with Shaded Weave Structure. TeXtile Research Journal, 84, 1820-1828. https://doi.org/10.1177/0040517514527377

[8] Qi, Y., Zhang, A.D. and Zhou, J. (2017) Design of Jacquard Fabric of Tie-Dye Art Style Based on Two-Weft Compound Weave Structure. Journal of Silk, 54, 57-60.

[9] Wang, J.C., Yang, B., Huang, B.H. and Jin, Z.M. (2012) Design and Development of Polymeric Optical Fiber Jacquard Fabric with Dynamic Pattern Display. Textile Research Journal, 82, 967-974. https://doi.org/10.1177/0040517511427965

[10] Wang, Q. and Zhu, C.Y. (2016) Design Principle and Method of Weaving Structure of Jacquard Fabrics with Quilting Seam Effect. Journal of Silk, 53, 51-55.

[11] Li, Q.Z., Zhang, H.X., Zhu, C.Y. and Ma, T.F. (2012) Research and Product Development of Jacquard Fabric Imitating the Embroidered Effect. Journal of Silk, 49, 41-44. 